
November 1934

\title{
EFFECT OF COLD-ROLLING ON THE INDENTATION HARDNESS OF COPPER
}

\author{
By John G. Thompson
}

ABSTRACT

Specimens of tough-pitch electrolytic copper, commercial oxygen-free copper, and single crystals of copper of different orientations, were subjected to severe cold-rolling to determine the effect on the properties, particularly on the hardness. In all cases the indentation hardness increased to a maximum value which was maintained during subsequent reduction until the hardness determinations became unreliable owing to the thinness of the specimens. No irregularities were encountered except in the case of very thin specimens. The results were confirmed by determinations of tensile strength of some of the specimens and by the application of Meyer's analysis to some of the data. The effect of severe coldrolling on the indentation hardness of copper was not materially affected by the initial thickness of the specimen, the presence or absence of 0.4 percent of oxygen, the change from polycrystalline to single crystal specimens, or the orientation of the single crystals with respect to the plane of deformation.

\section{CONTENTS}

I. Thtroduction Page

II. Materials and procedure

III. Cold-rolling and hardness

1. Hot-rolled electrolytic copper

2. Commercial oxygen-free copper

3. Single crystals of copper

IV. Summary

V. References.... 756

\section{INTRODUCTION}

The effect of severe cold-working on the properties, particularly on the hardness, of metals such as copper has been the subject of extended discussion. It is common knowledge that moderate amounts of coldwork materially increase the hardness and tensile strength of many metals, but that an excessive amount of cold-work may result in the development of internal or external structural defects which seriously impair the mechanical properties.

Several years ago Rawdon and Mutchler (3) ${ }^{1}$ interpreted results of hardness measurements of severely cold-rolled strips of copper as indicating the attainment of maximum hardness after a moderate amount of reduction by cold-rolling, after which further reduction was accompanied by a progressive decrease in hardness. In the discussion

\footnotetext{
1 The figures given in parentheses here and throughout the text correspond to the numbered references, arranged in chronological order, at the end of this paper.
} 
of their paper the reversal of hardness of copper during progressive cold-rolling was stated to be contrary to commercial experience. Subsequently, Moore (4), Fogler and Quinn (6), Hoyt and Schermerhorn (7), Malam (12), Sandifer (16), and Kawai (18) failed to find irregularities or a reversal in the hardness of copper during cold-rolling, and Harris (13) and Smith (21) found that the tensile strength of copper increased regularly with increasing amounts of cold-work. On the other hand, anomalous behavior of copper during cold-rolling was reported by Alkins (1), and subsequently by O'Neill and Cuthbertson (20) who ascribed irregularities in the ball-indentation hardness values to observational errors resulting from the ridge of metal which was extruded around the ball in the case of specimens taken during certain stages of cold-rolling when reorientation of the crystals was taking place. Johnson (2) found a reversal in hardness of copper and the results of Körber and Hoff (14) showed that both the tensile strength and Brinell hardness of cold-rolled copper rose to a maximum and subsequently declined, although the decrease was not as pronounced as was reported by Rawdon and Mutchler. In a discussion Herbert (9) reported that the hardness of a number of metals increased to a maximum and then declined, during the application of the pendulum hardness tester, although the total decrease in hardness was slight.

In addition to the illustrations cited of anomalous behavior in copper, an example of the existing uncertainty is found in the varying reports of the maximum hardness attainable through cold-rolling. For example, the maximum Brinell number for copper may be 130 according to Moore (4), 109 according to Körber and Hoff (14), or about 114 according to Smith (21). Part of these differences presumably originate in the different ball diameters and loads employed.

A number of suggestions have been offered to account for this apparently anomalous behavior of copper. Spontaneous annealing during rolling has been accepted to explain the work softening of metals such as cadmium (17) or lead alloys $(11,15,19)$, but this possibility apparently did not apply to copper, as Rawdon reported additional experiments in which similar behavior was observed when the rolls and specimens were cooled with iced brine throughout the rolling operation. It was suggested that the hardness of copper after coldrolling might be dependent upon the original thickness and hardness of the material, by the details of rolling procedure such as the roll diameter and amount of reduction per pass, and that the determinations of hardness might be influenced by the anvil effect and by sources of error inherent in the determination of ball-indentation hardness values. The use of Meyer's analysis (5) to verify the simple determinations of Brinell hardness was suggested (8). The possible effect of aging phenomena was discussed, but it was agreed $(3,6,7)$ that copper does not age-harden appreciably after rolling.

The present investigation was undertaken to study the effect of some of these factors on the hardness-reduction relation for copper.

\section{MATERIALS AND PROCEDURE}

Cold-rolling experiments were conducted on various specimens of copper, including electrolytic copper in the cast and in the hot-rolled conditions, commercial oxygen-free copper, and single crystals of 
oxygen-free copper. Specimens varying in initial thickness from 0.2 to 3.0 inches were rolled to thicknesses of 0.02 inch or less, without intermediate annealing. Three two-high rolling mills were available, equipped, respectively, with rolls 2,5 , and 16 inches in diameter. Relatively light reductions per pass were employed in all of the rolling experiments, in order to avoid heating and possible consequent annealing during the rolling operations. In spite of the light reductions, the bars frequently were warm to the touch as they emerged from the rolls, but whenever this occurred the bars were cooled in ice water after each pass through the rolls.

The 16-inch mill was used for all specimens thicker than 0.5 inch. Rolling was continued in this mill down to thicknesses of about 0.2 inch, with specimens between 0.5 and 0.2 inch in thickness receiving light finishing passes in the 5-inch mill in order to improve the surface for the hardness determinations. In addition to these finishing passes, the 5 -inch mill was used for rolling specimens of 0.5 inch or less initial thickness in the annealed condition, and to complete the rolling of specimens previously reduced to about 0.2 inch in thickness in the 16-inch mill. Rolling in the 5 -inch mill usually was continued until the specimens were about 0.005 inch in thickness. The 2 -inch handoperated mill was used for a few experiments on material 0.4 inch or less in initial thickness, in the soft condition.

In all cases the difficulty of rolling increased rapidly to a maximum at a reduction of approximately 50 percent from the original thickness, or at a reduction ratio ${ }^{2}$ of about 2 , and then decreased on further reduction. This difficulty in rolling was the result primarily of the tendency of the copper to curl and consequently to emerge from the rolls in a series of waves rather than in a flat strip. Subsequent determinations of hardness showed that this curling tendency was not due to the development of maximum hardness, in fact the curling was most noticeable when the material was approximately half-hard and disappeared before maximum hardness was attained. The tendency is perhaps associated with the penetration of work-hardening to the center of the specimen.

Corner cracks, which developed rather frequently during such severe cold-rolling, were removed by filing or machining before they spread across the strip.

Coupons were removed at suitable intervals during the rolling of each specimen. Hardness determinations were made on the rolled surfaces of the coupons, without additional polishing which might have influenced the results of determinations under the light loads which were used. Both Vickers and Brinell numbers were determined, each under a variety of loads. The Vickers and Brinell results in all cases yielded similar curves for the hardness-reduction relation although the Vickers numbers usually were higher than the Brinell numbers for the same specimen. For the sake of brevity only the Vickers results are discussed in this paper.

The Vickers numbers were determined by means of a diamond pyramid indenter under loads of from 5 to $30 \mathrm{~kg}$, with each load

${ }^{2}$ In Rawdon and Mutchler's paper (3) the hardness numbers were plotted against reduction ratio instead of against percent reduction, in order to emphasize the changes which occurred at higher reductions. This reduction ratio $=\frac{T 0}{T}$ where $T o=$ initial thickness of specimen, and $T=$ thickness after rolling. The use of reduction ratio rather than percent reduction has been found convenient to express results in the majority of cases throughout this paper. 
applied to the indenter for a period of 10 seconds. Four or more impressions were made on each specimen; both diagonals of each impression were measured; and the eight or more measurements were averaged to obtain a single Vickers number for the specimen from the formula

where $V_{N}=$ the Vickers number

$$
V_{N}=\frac{P}{A}=\frac{2 P \sin 68^{\circ}}{l^{2}}=\frac{1.854 P}{l^{2}}
$$

$P=$ applied load, in $\mathrm{kg}$

$A=$ area of contact between the $136^{\circ}$ indenter and the specimen

$l=$ length of the diagonal of the indentation, in $\mathrm{mm}$

The Vickers numbers reported in this paper were obtained from specimens supported on a hard (plate glass) anvil. It is believed that these numbers were not influenced by the anvil. A study was made of the effect of the anvil, by using a soft (annealed copper) anvil in addition to the hard anvil; this study will be reported in another paper.

\section{COLD-ROLLING AND HARDNESS}

A few attempts were made to cold-roll electrolytic copper directly from the soft, cast condition in order to avoid any complications which might result from the customary hot-rolling of cast copper. It was soon evident, however, that the desired amount of cold-work could not be satisfactorily attained with the coarsely crystalline cast copper used.

\section{HOT-ROLLED ELECTROLYTIC COPPER}

A 200-pound bar of selected electrolytic copper, containing 0.40 percent oxygen, was the basic material for the next series of experiments. The bar had been reduced by hot-working to 50 percent of the thickness of the original cast bar. The Brinell number of the material, as received, was about 60 (1/16-inch ball, 15-kg load). Small bars for cold-rolling were cut from the large bar in such fashion that the planes of rolling for subsequent cold-rolling operations were the same as for the original hot-rolling. The small bars were annealed about $2 \frac{1}{2}$ hours at $300^{\circ} \mathrm{C}$, which reduced the hardness number to about 50 without appreciably increasing the grain size.

Bars ranging from 3 to 0.2 inch in initial thickness were cold-rolled without intermediate annealing to final thicknesses between 0.02 and 0.005 inch, coupons for the determination of indentation hardness being removed at suitable intervals during the rolling operations. Representative schedules for the rolling of tough-pitch electrolytic copper and for the other forms of copper used in this investigation are shown in table 1. Both Brinell and Vickers numbers, under a variety of conditions, were determined for these coupons but the present paper is limited to a discussion of the Vickers numbers of some of the sets of coupons, selected to illustrate the hardness-reduction relations which were consistently indicated by all the data. The effect on the Vickers hardness (10-kg load) of copper of cold-rolling from initial thicknesses between 0.2 and 3 inches to final thicknesses of 0.02 inch or less, is shown in figure 1 . 


\begin{tabular}{|c|c|c|}
\hline \multirow{4}{*}{ 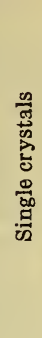 } & 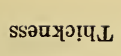 & 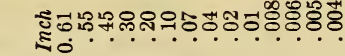 \\
\hline & uо!ฺпрәч & 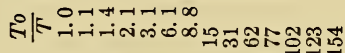 \\
\hline & i Sossed $_{d}$ & 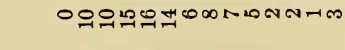 \\
\hline & $\begin{array}{l}\text { : } \\
\text { 옳 } \\
\text { ठ }\end{array}$ & 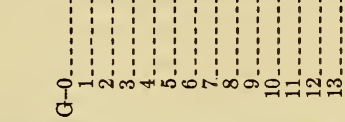 \\
\hline
\end{tabular}

\begin{tabular}{|c|c|c|}
\hline \multirow{5}{*}{ 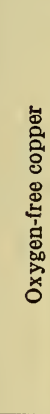 } & ssəuฯว!ุL & క్షు \\
\hline & \multirow{2}{*}{ 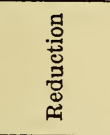 } & 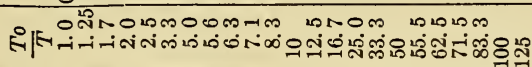 \\
\hline & & 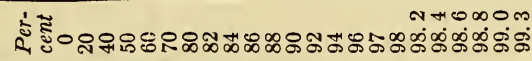 \\
\hline & I SOSSE d & 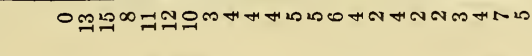 \\
\hline & $\begin{array}{l}\text { : } \\
\text { ठี } \\
\text { ठे }\end{array}$ & 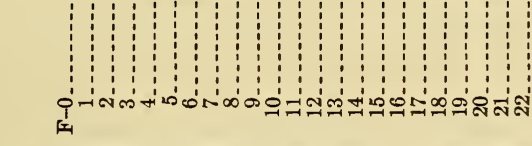 \\
\hline
\end{tabular}

งsวนมวนเ

\begin{tabular}{|c|c|}
\hline นо!ฺอก & 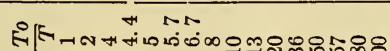 \\
\hline
\end{tabular}

\begin{tabular}{|c|c|}
\hline S SOSSE & ○ \\
\hline
\end{tabular}

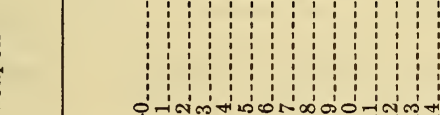

1.

递

\begin{tabular}{|c|c|}
\hline 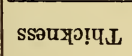 & 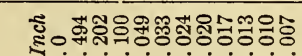 \\
\hline
\end{tabular}

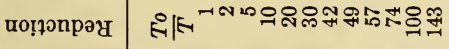

\begin{tabular}{|c|c|}
\hline I $\operatorname{sesse}_{\mathrm{d}}$ & 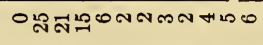 \\
\hline
\end{tabular}

:

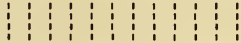

ơnmononoson=

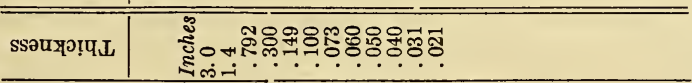

uo!̣onpəy

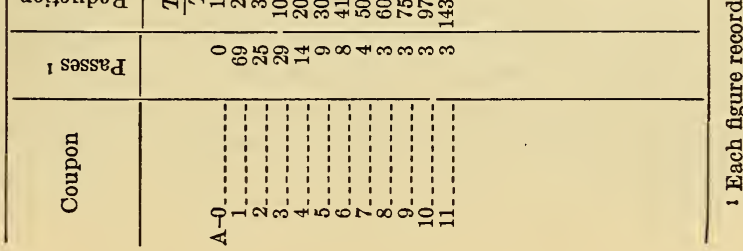


The results indicated that the indentation hardness of copper increased rapidly and continuously during the first stages of coldrolling, in subsequent stages the hardness continued to increase but at a slower rate until a maximum hardness was reached, after which the hardness remained constant during further reduction. The only irregularities encountered were variations in hardness of some of the coupons obtained during the stages when the specimens curled badly during rolling. The maximum hardness number in all cases was between 120 and 130 and was independent of the initial thickness of specimen used. Although the plotted results indicated some differences in the rate at which the maximum hardness was attained, in

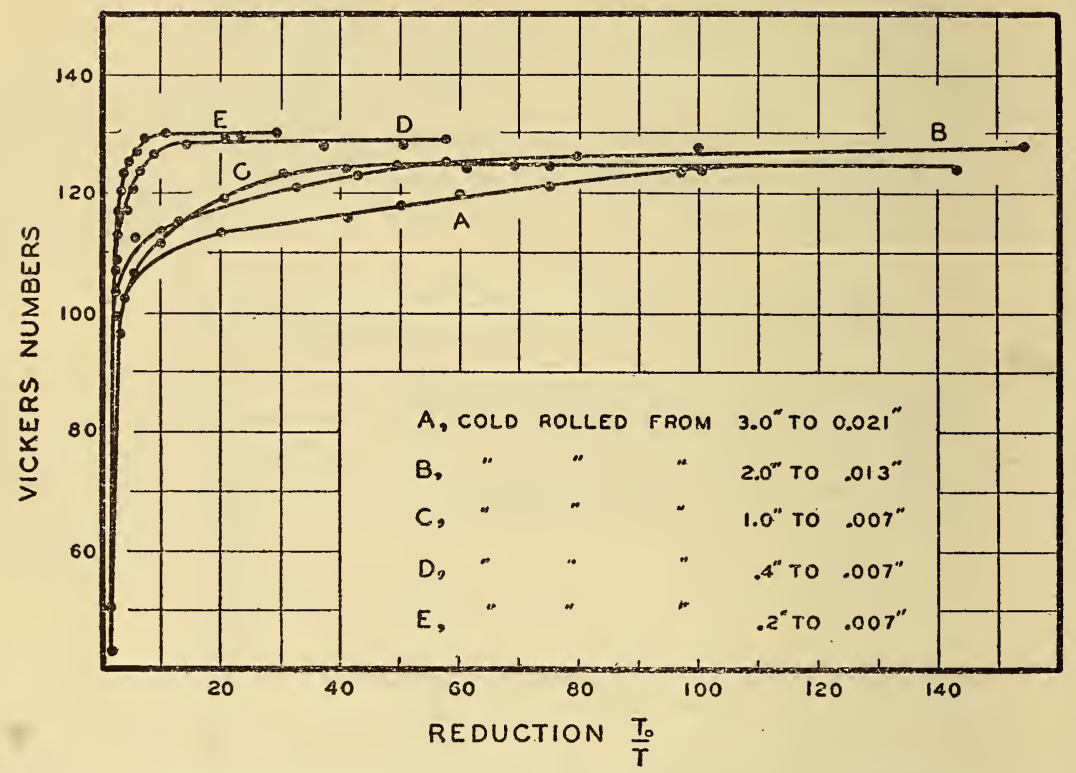

FIGURE 1.-Effect of cold-rolling on the indentation hardness of tough-pitch electrolytic copper.

general, variations in initial thickness of the specimen did not appear to affect materially the general characteristics of the hardnessreduction relation. Likewise, there was no material difference observed in the results obtained from rolling in the 5-inch and 16-inch mills. To study further the effect of roll diameter on the hardness of electrolytic copper, annealed bars 1 inch wide, 6 inches long, and either 0.2 or 0.4 inch thick were rolled between rolls 2 inches in diameter, in a hand-operated mill, closely approximating the conditions of Rawdon and Mutchler's experiments. Great difficulty was encountered in the operation of these hand rolls, as a result of the tendency of the specimens to curl during certain stages of reduction. This curling tendency led to inconsistent results in the determination of hardness; for example, a coupon might be five or more Brinell units harder on the convex side than on the concave surface. In general, however, the hardness-reduction relation corresponded with that of the curves in figure 1. 
A number of coupons were examined for uniformity of hardness throughout the cross section. The results of the Vickers hardness determinations indicated that the center of the bar was softer than the rolled surfaces during the initial stages of reduction but that reduction of 50 percent, equivalent to a reduction ratio of 2 , from initial thicknesses of 3 inches or less produced uniform hardness throughout the cross section.

\section{COMMERCIAL OXYGEN-FREE COPPER}

Specimens of commercial oxygen-free copper were cold-rolled to compare the hardening of this material with the results obtained for electrolytic copper. The commercial oxygen-free copper, in the form of bars 12 by 2 by 0.5 inches of hot-rolled material, was obtained through the courtesy of the United States Metals Refining Co. These bars were cold-rolled in the 5-inch mill without annealing to thicknesses of about 0.005 inch, under rolling schedules (table 1) similar to those employed for electrolytic copper. The rolling was accomplished with noticeably less difficulty than was encountered with tough-pitch electrolytic copper; the tendency to curl during rolling was less pronounced, and side splits and corner cracks were almost entirely absent.

The effect of progressive cold-rolling on the Vickers number of oxygen-free copper is shown in figure 2. The change in Vickers hardness (10-kg load) was continuous with increasing reduction until maximum hardness was reached. The initial stages of reduction were accompanied by a rapid increase in hardness until a maximum hardness number approaching 130 was reached. The maximum hardness, once attained, was maintained during further reduction until the specimens became so thin that hardness determinations were unreliable. These results are similar to those obtained for material which contained 0.4 percent oxygen; evidently the presence or absence of 0.4 percent oxygen does not affect the hardening of copper during cold-rolling.

The changes in tensile strength and in elongation, as a result of cold-rolling, also were determined on the coupons of oxygen-free copper. Flat specimens with a 2 -inch gage length, 0.5 inch in width, were used; the central portion of the gage length was further reduced in width by 0.002 inch to insure breaking between the gage marks. The specimens were tested on a hydraulic-type universal testing machine at a rate of travel of the crosshead of 0.1 inch per minute. Wedge grips were used for the thicker specimens and self-alining grips for the thinner ones. Only two specimens were available for each thickness of copper but in general satisfactory duplication of results was obtained.

The results of the tensile tests, also shown in figure 2 , in several respects confirmed the results of the hardness determination.s. The tensile strength increased rapidly during the first reductions and less rapidly during subsequent reductions. The hardness reached a maximum and thereafter remained constant, but the tensile strength increased continuously throughout the reduction, the thinnest coupon, 0.004 inch thick, yielding the highest tensile strength, 72,000 pounds. The elongation decreased rapidly from an initial value of about 25 percent to about 3 percent and thereafter remained constant at 
about 3 percent, within the limits of experimental error. These results are not in accord with results reported by Körber and Hoff (14) who found that the tensile strength and Brinell number of copper reached maxima at a thickness of 0.047 inch, representing a reduction of between 90 and 98 percent, and then decreased slightly on further

THICKNESS, INCH

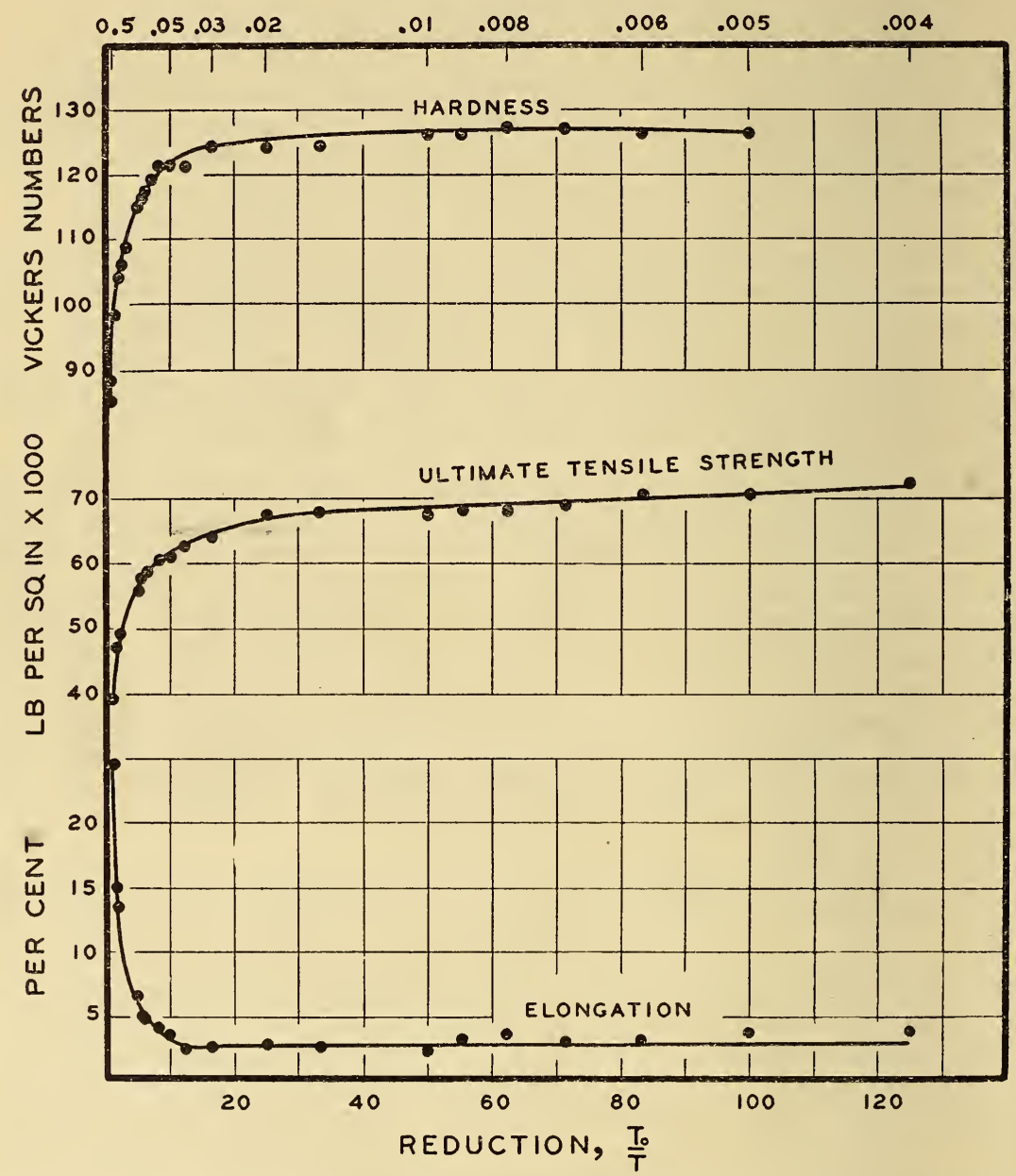

Figure 2.-Effect of cold-rolling on the indentation hardness, tensile strength, and elongation of oxygen-free copper.

reduction. In the present experiments the Vickers numbers did not fall off until specimens thinner than 0.005 inch were encountered and the tensile strength was still increasing when a specimen thickness of 0.004 inch was reached. 
The application of Meyer's analysis ${ }^{3}$ to the Vickers hardness results, under loads of from 5 to $30 \mathrm{~kg}$ further confirmed the fact that the indentation hardness of oxygen-free copper increased steadily with increasing reduction, at least until the thickness had been reduced to 0.005 inch. The results of Meyer's analysis have been plotted in figure 3, using percent reduction values for abscissas, to emphasize the changes during the early stages of rolling. The " $a$ " values increased steadily to a maximum value of about 70 ; the " $n$ " value was approximately 2 at 20-percent reduction, and remained constant thereafter until the thickness had been reduced to 0.005 inch. No reversal of hardness was indicated and the " $n$ " values showed that the material was completely work-hardened to the depth affected by

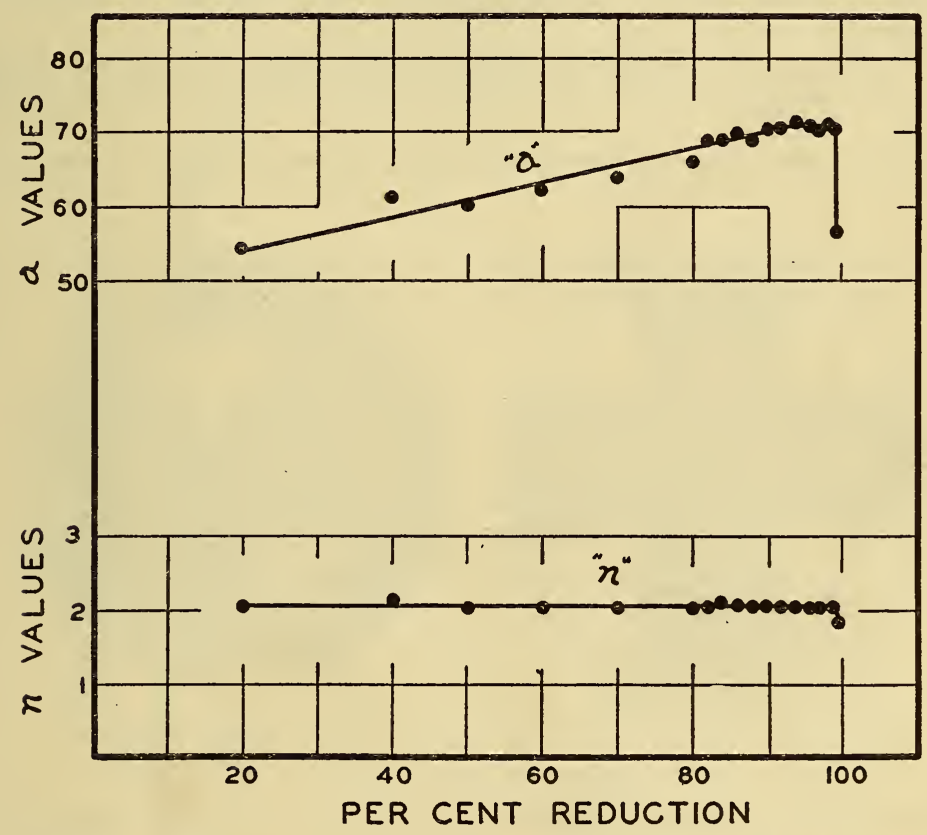

FIGURE 3.-Meyer's analysis of the indentation-hardness determinations for oxygen-free copper.

the Vickers indentations, by relatively slight reduction. This is in accord with the conclusions of Harris (13) regarding the skin effect in hard-drawn copper wire.

\section{SINGLE CRYSTALS OF COPPER}

Tough-pitch electrolytic copper was melted in an elongated graphite crucible, to form a rod about 0.6 inch in diameter and about 5 inches long. Such rods prepared in an Arsem vacuum furnace were practically oxygen free, several analyses showing that less than 0.001 percent oxygen was present. By suitable control of the rate of cooling, it

${ }^{3}$ See the paper by S. L. Hoyt (5) for the detailed procedure of Meyer's analysis as applied to indentation hardness impressions. Meyer's equation for the relation between load and diameter of indentation is

Consequently his method of expressing indentation hardness requires the determination of two factors, $a$ and $n$. 
was possible to produce a rod the lower end of which consisted of a single crystal of copper 0.6 inch in diameter and about 3 inches in length. A number of these single crystal rods were prepared and one end of each rod was machined to a hemisphere. The hemispherical ends were blank etched ${ }^{4}$ in 1:1 nitric acid containing a few crystals of ferric chloride, to remove the work-hardened surface resulting from the machining operation. Subsequent etching in ammonia and hydrogen peroxide developed the four-leaf clover pattern of the dodecahedral faces, from which the orientation of the single crystal with respect to the long axis of the rod was estimated. For this study accurate determinations of the crystal orientation, by means of X-ray or other precise methods, was not required; the approximate orientation established by the etching method was sufficient.

Two rods were selected, in one of which the clover-leaf pattern was approximately symmetrical with respect to the long axis of the

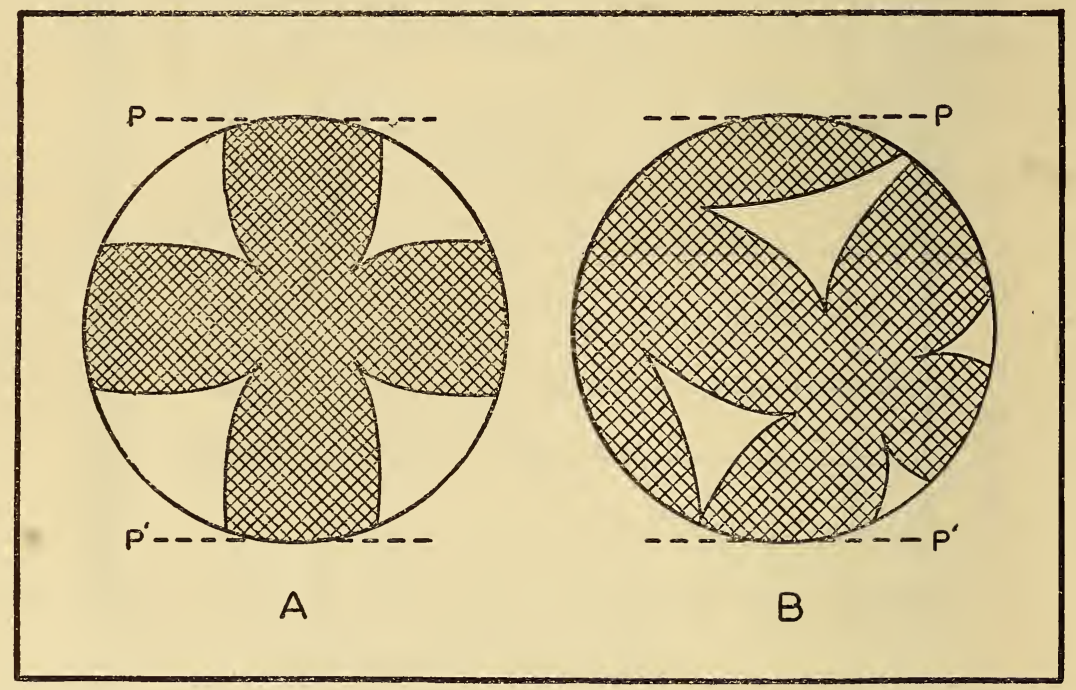

FIGURE 4.-Etched patterns indicating the orientation in single-crystal rods of copper.

rod, figure 4 (A), whereas in the other it was not, figure 4 (B). By selecting the proper positions on the circumference of each rod, to define the rolling planes $\mathrm{P}$ and $\mathrm{P}^{\prime}$ in figure 4 , it was possible to roll one rod so that the planes of rolling coincided within about 8 degrees with the plane of a cube face; in the other rod the plane of rolling was located between and intersecting the 100 and 110 planes. The 2 rods were cold-rolled in practically identical steps, according to the schedule in table 1. There was no appreciable difference detected in the rolling characteristics of the 2 crystals; both rolled easily and satisfactorily.

Some interesting qualitative information was obtained by reetching the hemispherical ends of the rods at different stages of the

4 The blank etching and the selective etching to develop the pattern of the dodecahedral faces followed the procedure of Hausser and Scholz (10). 
rolling operations. When the plane of rolling coincided with a cube face of the crystal, as in figure $4(\mathrm{~A})$, reductions shortened the 2 vertical leaves without affecting the 2 horizontal leaves, until a thickness of 0.2 inch was reached. The original pattern could be restored by reetching although at this point the 2 vertical leaves were almost entirely gone, and the plane of rolling was beginning to encroach upon the horizontal leaves. Etching of specimens thinner than 0.2 inch was not attempted. The survival of the horizontal leaves may indicate that this rolling procedure affected only the layers

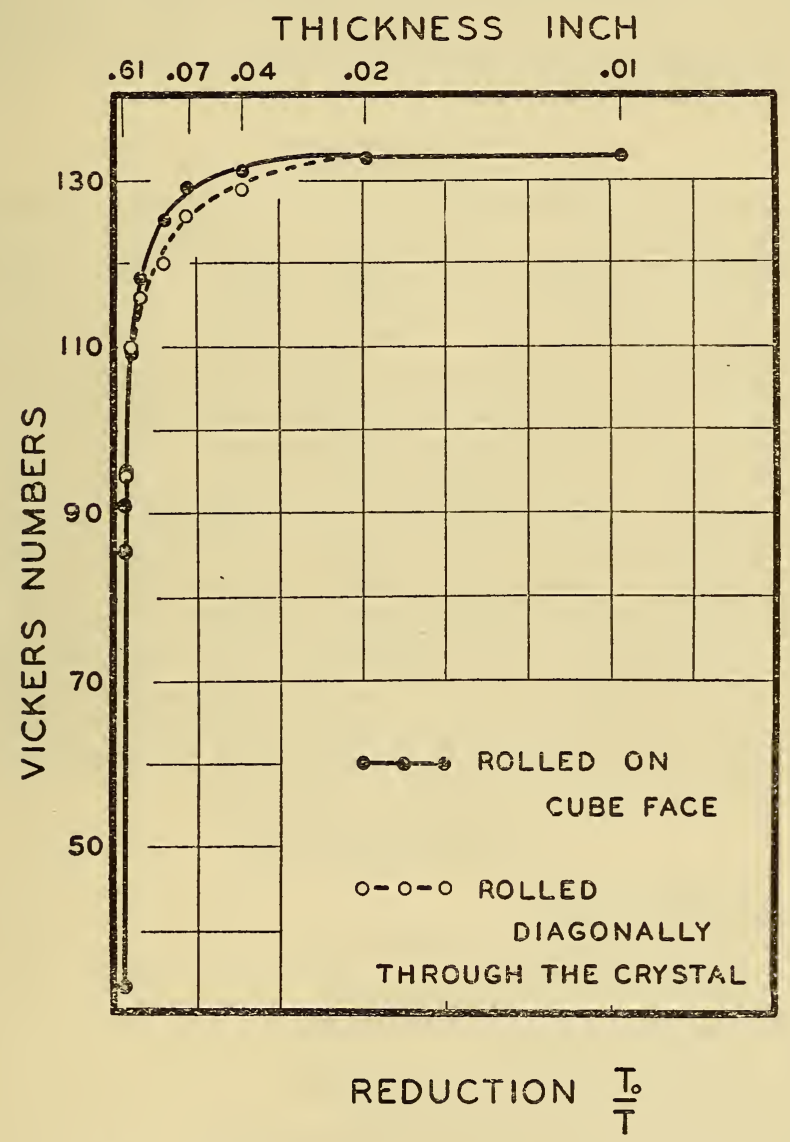

Figure 5.-Effect of cold-rolling on the indentation hardness of single crystals of copper.

of metal in contact with the rolls. On the other hand, it is possible that horizontal displacement of layers of metal could occur without destroying the etched pattern. Consequently it is not known whether the pattern developed on the end of the cold-worked rod represents the unchanged remainder of the original single crystal or whether it represents the result of a process of slippage and distortion. Somewhat similar results were obtained for the rod which was rolled diagonally through the crystal, although the etched pattern, figure 4 (B), was not as easily identified as was the symmetrical pattern of figure 
4 (A). For a satisfactory explanation of these observations, a more precise study by X-ray or other methods is necessary.

Vickers numbers were determined to compare the effects of coldrolling single-crystal and polycrystalline copper, and to see if there was any difference, on account of orientation, in the hardening of the 2 crystals by cold-work. The rate of change in hardness of the 2 crystals was almost identical as shown in figure 5 . Evidently orientation did not exert a pronounced effect on the rate of hardening of copper as a result of cold-work. A comparison of the hardness-reduction curves and of the maximum-hardness numbers attained for mono and polycrystalline copper, indicated that the rate and amount of hardening by cold-work were not materially affected either by the size or number of the crystals of copper.

\section{SUMMARY}

The effect of severe cold-rolling on the indentation hardness of copper was determined for specimens of tough-pitch electrolytic copper, commercial oxygen-free copper, and for two single-crystal rods of different orientations. Similar hardness-reduction relations were observed in all cases; the hardness numbers increased with reduction, rapidly at first and then less rapidly as the maximum hardness was approached. The maximum hardness once attained was maintained during further cold-work until the specimens became so thin that determinations of indentation hardness were unreliable. These conclusions were substantiated by determinations of the tensile strength of specimens of one of the grades of copper used and by the application of Meyer's analysis to some of the hardness data. The effect of cold-work on the indentation hardness of copper was not appreciably influenced by the orientation of the rolling plane with respect to the crystalline lattice structure in single-crystal specimens, by the change from single crystal to polycrystalline material, by the presence or absence of 0.4 percent oxygen, or by changes, between 0.2 and 3 inches, in initial thickness of specimen.

\section{REFERENCES}

1. J.Inst. Metals 23,381(1920).

2. J.Inst. Metals $\mathbf{2 3 , 4 4 3 ( 1 9 2 0 ) \text { . }}$

3. Trans.Amer.Inst. Min.Met.Eng. \%0,342(1924).

4. J.Inst. Metals 32[2],407(1924).

5. Trans.Amer.Soc.Steel Treating 6,396(1924).

6. Trans.Amer.Inst. Min.Met.Eng. $71,889(1925)$.

7. J.Inst. Metals 35[1],231(1926).

8. Trans.Amer.Inst.Min.Met.Eng. 73,657(1926).

9. Trans.Amer.Soc.Mech.Eng. 48,705(1926).

10. Wiss.Veröff.a.d.Siemens-Konzern 5[3],144(1926-27).

11. J.Inst.Metals 38,315(1927).

12. J.Inst.Metals 40,375(1928).

13. Proc.Amer.Inst.Min.Met.Eng.Inst.Metals Div. 78,518(1928).

14. Mitt.K.W.Inst.Eisenforschung 10,175(1928).

15. J.Inst. Metals 41,257(1929).

16. J.Inst. Metals 44,115(1930).

17. J.Inst. Metals 45,307(1931).

18. Sci.Rep.Tohoku Imp.Univ. 20,681(1931).

19. J.Inst. Metals 46,139(1931).

20. J.Inst. Metals 46,273(1931).

21. National Metals Handbook p.1186(1933 edition).

Washington, June 29, 1934. 